\title{
Melancholy and the claim for relation
}

\author{
Giorgio Bordin
}

Received: 11 February 2011/Accepted: 15 February 2011/Published online: 16 March 2011

(c) Springer-Verlag 2011

Within the full range of diseases, madness has ever been a challenge for physicians, in perennial oscillation between science and magic, natural and supernatural, body and soul. The history of melancholy helps us in a better understanding of this aspect of medicine.

Melancholy has cultural and etymological roots deep in the doctrine of the four humours (Hippocrates): melancholia (literally black bile) refers to mental disturbation, and in the Middle Ages was considered as sloth or laziness: a capital sin. Until the seventeenth century, treatises primarily dealt with the relationship between disease and sin, between the humours of the body and witchcraft, between reason and passion. In the Renaissance, its aspect of sweet reflection and sorrow that pervades a person's character making him/her perceptive and introspective, became also the character of the artist, whose outlook appeared to combine elements from dreams, meditation, magic and alchemy. In his famous etching: "Melancholy", Dürer depicts a young woman contemplative and musing, as the result of the contrast between an attraction to celestial ideas and the intellectual perception of the self, as fragile and finite. During the nineteenth century, the melancholic character pervaded the decadent romanticism of novels, while the new studies of psychiatry and psychoanalysis in the twentieth redefined melancholy as an affective disorder and from then on it was defined more properly as depression. This continuous wax and wane from and through material and immaterial explanation of origin of madness, this difficult balance between repulsion and allure, ethical outrage or scientific coolness witnesses the ultimate disproportion between medical science and the very nature of disease, which refuses to be classified in stiff nosological grids.

G. Bordin ( $\square)$

Parma, Italy

e-mail: giorgio.bordin@fastwebnet.it

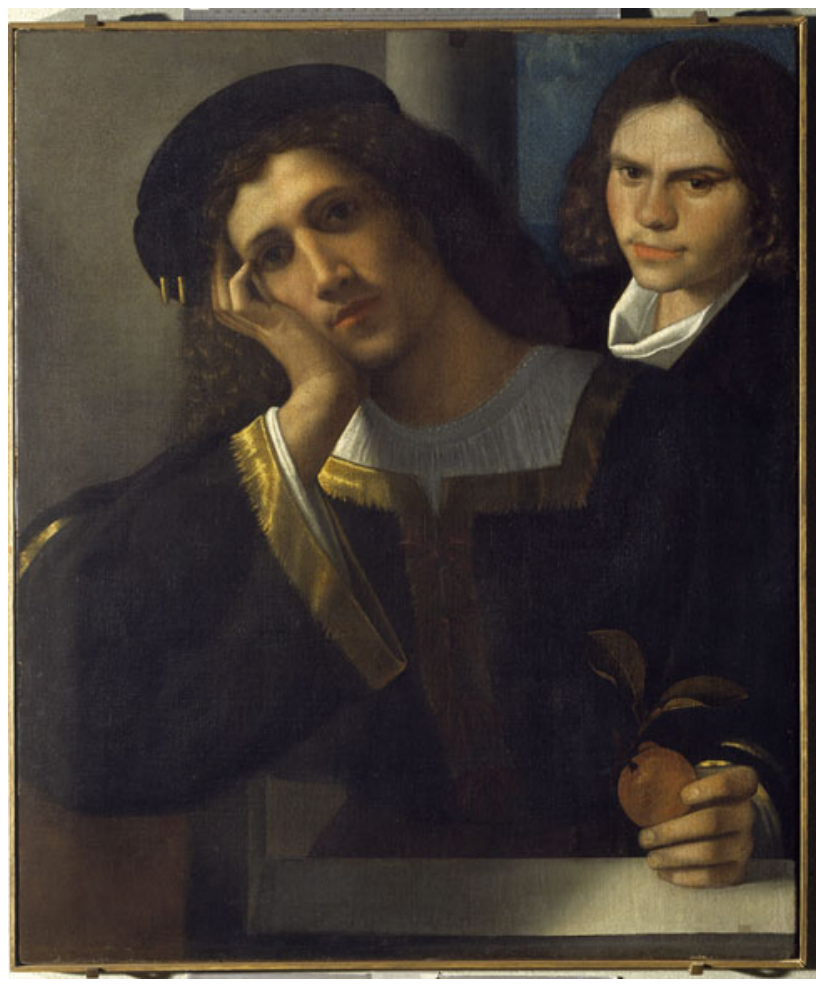

Fig. 1 Giorgione. Double portrait, Oil on canvas, cm $80 \times 75.1502$ ca. Museo di Palazzo Venezia Rome, with permission, (C) Foto Scala Firenze 2011

This nature of the human soul which overwhelms a simplistic definition of the whole dimension of man is sometimes addressed by the idea of the double, which in art emerges in this Giorgione's double portrait. Two faces, one person. The first, elegant and thoughtful, takes the gesture of Dürer's woman of "Melancholy", defining the mood of the young fellow. He is turned toward us but does not watch to us: he is watching his Self. The left hand holds a 
wild orange, meaning that his thoughts deal with love. The other young man is the remaining half: real, not idealized, he turns the gaze to us to ask the great claim which underlies each relation: who really do you think I am? Me or my disease? 